\title{
Guideline
}

\section{Guidelines for Laboratory Diagnosis of Coronavirus Disease 2019 (COVID-19) in Korea}

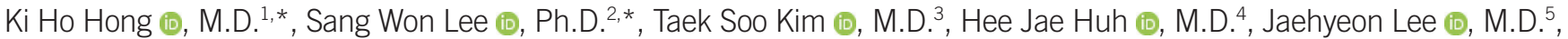

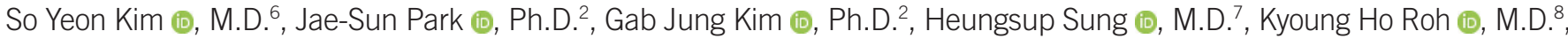

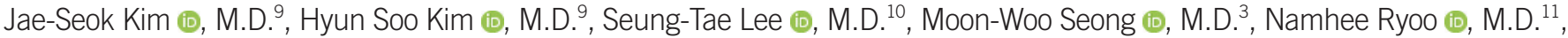

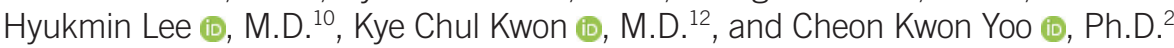

\section{On behalf of}

Korean Society for Laboratory Medicine, COVID-19 Task Force and the Center for Laboratory Control of Infectious Diseases, the Korea Centers for Disease Control and Prevention

${ }^{1}$ Department of Laboratory Medicine, Seoul Medical Center, Seoul, Korea; ${ }^{2}$ Center for Laboratory Control of Infectious Diseases, Centers for Disease Control and Prevention, Osong, Korea; ${ }^{3}$ Department of Laboratory Medicine, Seoul National University Hospital, Seoul, Korea; ${ }^{4}$ Department of Laboratory Medicine and Genetics, Samsung Medical Center, Sungkyunkwan University School of Medicine, Seoul, Korea; ${ }^{5}$ Department of Laboratory Medicine, Jeonbuk National University Medical School and Hospital, Jeonju, Korea; ${ }^{6}$ Department of Laboratory Medicine, National Medical Center, Seoul, Korea; ${ }^{7}$ Department of Laboratory Medicine, Asan Medical Center and University of Ulsan College of Medicine, Seoul, Korea; ${ }^{8}$ Department of Laboratory Medicine, National Health Insurance Service, Ilsan Hospital, Goyang, Korea; ${ }^{9}$ Department of Laboratory Medicine, Hallym University College of Medicine, Chuncheon, Korea;

${ }^{10}$ Department of Laboratory Medicine, Yonsei University College of Medicine, Seoul, Korea; ${ }^{11}$ Department of Laboratory Medicine, Keimyung University School of Medicine, Daegu, Korea; ${ }^{12}$ Department of Laboratory Medicine, College of Medicine, Chungnam National University, Daejeon, Korea

The outbreak of coronavirus disease 2019 (COVID-19), which began in December 2019, is still ongoing in Korea, with >9,000 confirmed cases as of March 25, 2020. COVID-19 is a severe acute respiratory syndrome Coronavirus 2 (SARS-CoV-2) infection, and real-time reverse transcription-PCR is currently the most reliable diagnostic method for COVID-19 around the world. Korean Society for Laboratory Medicine and the Korea Centers for Disease Prevention and Control propose guidelines for diagnosing COVID-19 in clinical laboratories in Korea. These guidelines are based on other related domestic and international guidelines, as well as expert opinions and include the selection of test subjects, selection of specimens, diagnostic methods, interpretation of test results, and biosafety.
Key Words: COVID-19, Outbreak, Laboratory diagnosis, Guidelines, Korea
Received: March 16, 2020

Revision received: March 17, 2020

Accepted: March 25, 2020

Corresponding author: Hyukmin Lee, M.D. Department of Laboratory Medicine, Yonsei University College of Medicine, 50-1 Yonseiro, Seodaemun-gu, Seoul 03722, Korea

Tel: +82-2-2228-2446

Fax: +82-2-313-0956

E-mail: HMLEE71@yuhs.ac

\section{Co-Corresponding Author:}

Cheon Kwon Yoo, Ph.D.

Center for Laboratory Control of Infectious Diseases, Centers for Disease Control and Prevention Osong Health Technology Administration Complex, 187 Osongsaengmyeong 2-ro, Osonge-eup, Heungdeok-gu, Cheongju 28159, Korea Tel: +82-43-719-8100

Fax: +82-43-719-8149

E-mail: ckyoo@korea.kr

*These authors equally contributed to this study.

\section{(1) (\$)}

(c) Korean Society for Laboratory Medicine

This is an Open Access article distributed under the terms of the Creative Commons Attribution Non-Commercial License (https://creativecommons.org/licenses/by-nc/4.0) which permits unrestricted non-commercial use, distribution, and reproduction in any medium, provided the original work is properly cited. 


\section{INTRODUCTION}

In December 2019, a mass outbreak of Coronavirus disease 2019 (COVID-19) occurred in Wuhan, Hubei Province, People's Republic of China. Currently, the disease has spread to other regions of China and around the world [1]. In Korea, more than 9,000 patients have been confirmed as of March 25, 2020.

The World Health Organization (WHO) officially changed the name of the disease to coronavirus disease 2019 (COVID-19) from 2019 novel coronavirus (2019-nCoV) infection on February 11, 2020. The International Committee on Taxonomy of Viruses has proposed the name severe acute respiratory syndrome Coronavirus 2 (SARS-CoV-2) for the causative agent of COVID-19 [2]. This document uses COVID-19 and SARS-CoV-2, as well as 2019-nCoV infection as appropriate.

This document provides guidelines for diagnosing COVID-19 in human specimens. Some contents of this document, including new test methods, specimen selection, and biosafety recommendations, may be subject to revision later, with the emergence of new scientific evidence and based on expert review.

The guidelines presented here are based on the "Korea Laboratory Response and Preparedness for 2019 Novel Coronavirus Molecular Testing in Clinical Laboratories" project, which is a commissioned project aimed at establishing and managing COVID-19 diagnosis in hospital laboratories and commercial laboratory centers. All copyrights to these guidelines are owned by Korean Society for Laboratory Medicine (KSLM) and the Korea Centers for Disease Control and Prevention (KCDC).

\section{CASE DEFINITION}

The case definition is based on the 7th Edition (March 15, 2020) of the Guidelines on Response to Coronavirus Disease 2019 published by the KCDC [3]. This case definition applies to conditions at a "serious stage" crisis alert level, in which COVID-19 imported into Korea is spreading to local communities or throughout the nation. It may be revised later based on the incidence of confirmed domestic cases, results of epidemiological studies, and the level of epidemics. The definition of a suspected case and patient under investigation (PUI) can be changed according to newly updated information from the KCDC.

\section{Confirmed case}

Cases with confirmed infection according to the diagnostic criteria, irrespective of the clinical manifestation (diagnostic tests: COVID-19 real-time RT-PCR, virus isolation).

\section{Suspected case}

Cases with fever $\left(37.5^{\circ} \mathrm{C}\right.$ or higher) and/or respiratory symptoms (cough, sore throat, etc.) within 14 days of being in close contact with a confirmed case.

PUI

- Cases suspected of having COVID-19 based on a physician's opinion (e.g. pneumonia of unknown origin).

- Cases with fever $\left(37.5^{\circ} \mathrm{C}\right.$ or higher) and/or respiratory symptoms (cough, sore throat, etc.) within 14 days of visiting China (including the Special Administrative Regions of Hong Kong and Macau) or other COVID-19-affected countries (as listed on the WHO website).

- Cases showing epidemiological correlation with the domestic mass outbreak of COVID-19 and exhibiting fever $\left(37.5^{\circ} \mathrm{C}\right.$ or higher) and/or respiratory symptoms (cough, dyspnea, etc.) within 14 days.

\section{TEST INDICATIONS}

COVID-19 real-time RT-PCR may be performed for the purposes of:

\section{Confirming cases of suspected COVID-19}

\section{Deciding on the release of confirmed COVID-19 patients from quarantine}

The release criteria can be changed at any time according to newly updated information from the KCDC. See newly updated information on the KCDC website [3].

Screening asymptomatic individuals in close contact with confirmed COVID-19 patients

Although the importance of diagnosis in asymptomatic individuals who have been in close contact with confirmed COVID-19 patients remains unclear, diagnostic testing can be considered for the early detection of cases progressing to symptomatic infection.

\section{Differential diagnosis of cases with unknown respiratory syndromes}

The diagnostic testing may be performed for patients exhibiting pneumonia or respiratory syndromes with fever in order to identify the cause of the disease and to differentiate the condition from COVID-19. 
Table 1. Target genes of various real-time RT-PCR protocols (including the reagents approved for emergency use in Korea as of March 13, 2020) [5-9]

\begin{tabular}{lll}
\hline Authors, manufacturers & Target gene & Reference \\
\hline Corman, et al. & $E, R d R p$ & {$[6]$} \\
Chu, et al. & orflb, $N$ & {$[5]$} \\
Ministry of Public Health, Thailand & $N$ & {$[7]$} \\
Institut Pasteur & $E, R d R p$ & {$[8]$} \\
Centers for Disease Control and Prevention (USA) & $N$ & {$[9]$} \\
PowerCheck 2019-nCoV* (Kogene biotech, Seoul, Korea) & $E, R d R p$ & http://www.kogene.co.kr/ \\
Allplex 2019-nCoV* (Seegene, Seoul, Korea) & $E, R d R p, N$ & http://www.seegene.com/ \\
nCoV Real-Time Detection* (SD biosensors, Suwon, Korea) & $E, R d R p$ & http://sdbiosensor.com/ \\
DiaPlexQ 2019-nCoV*广 (Solgent, Daejeon, Korea) & orfla, $N$ & http://www.solgent.com/ \\
Real-Q 2019-nCoV* (BioSewoom, Seoul, Korea) & $E, R d R p$ & https:///biosewoom.com \\
\hline
\end{tabular}

*authorized for emergency use in Korea, as of Mar 13, 2020; ${ }^{\dagger}$ The correct positions of the targets were not provided by the manufacturer.

\section{METHODS FOR LABORATORY DIAGNOSIS}

\section{Real-time RT-PCR}

Globally, various real-time RT-PCR protocols have been proposed for the diagnosis of COVID-19 [4-11]; these protocols differ in the genes they detect. Further studies are needed to identify the optimal real-time RT-PCR protocol for diagnosing COVID-19 (Table 1).

Of the various protocols, some examine two genes using a two-step interpretation algorithm [5, 8, 12]. In these protocols, the identification of one gene is used as a screening test, while that of the second gene is used as a confirmatory test. In contrast, the results of other protocols, which examine three or more genes, are considered positive only when all genes are detected. If one of the genes is not detected in these protocols, the results are often interpreted as indeterminate or negative.

These guidelines were prepared based on the guidelines provided by the KCDC and the WHO [6], which recommend PCR amplification of the viral $E$ gene as a screening test and amplification of the $R d R p$ region of the orf $1 b$ gene as a confirmatory test.

As of March 13, 2020, KSLM and the KCDC recommend a positive result determination only when all the genes are detected, even for tests using different genes from those mentioned in the above two guidelines. This recommendation is based on the opinions of numerous experts who observed nonspecific and weak amplification in the clinical specimens of patients who received final results of COVID-19 as negative.

Clinical laboratories are recommended not to use methods other than real-time RT-PCR (pan-coronavirus PCR, serological tests, etc.) [13], laboratory-developed tests, and reagents that are not approved for emergency use by the Korea Ministry of Food and Drug Safety for diagnostic purposes.

\section{EMERGENCY USE OF AUTHORIZED REAGENTS}

As of March 13, 2020, several commercially available real-time RT-PCR reagents have been approved for emergency use in Korea for the in vitro diagnosis of COVID-19. Information on the approved reagents is available on the KCDC website (http:// www.cdc.go.kr).

The emergency use authorization (EUA) system is designed to respond to novel or emerging infectious diseases and is known for rapid evaluation and deliberation in emergency cases. Therefore, testing with approved reagents requires stringent and continuous quality control. The collection of data and specimens, as well as cross-testing of positive and negative specimens across laboratories are necessary to continuously analyze test performance.

All clinical laboratories should transfer their test results and all positive specimens to the KCDC. This is to ensure the quality control of reagents with EUA and laboratory surveillance of infectious diseases.

\section{SPECIMEN TYPES, SELECTION, AND COLLECTION}

\section{Types of specimens [13-18]}

General information

Repetitive testing may be necessary to confirm COVID-19 in 
Table 2. Specimens for COVID-19 testing $[4,18,19]$

\begin{tabular}{|c|c|c|c|c|}
\hline Types of specimens & Collection devices & Transport conditions & Storage conditions & Comments \\
\hline $\begin{array}{l}\text { Upper respiratory tract specimens: } \\
\text { NP swab*, OP swab*, and NP aspirate }\end{array}$ & Dacron or flocked swabs in VTM & $4^{\circ} \mathrm{C}$ & $\begin{array}{l}\text { Within } 5 \text { days: } 4^{\circ} \mathrm{C} \\
\text { Longer than } 5 \text { days: }-70^{\circ} \mathrm{C}\end{array}$ & \\
\hline $\begin{array}{l}\text { Lower respiratory tract specimen: } \\
\text { sputum* }\end{array}$ & Sterile container & $4^{\circ} \mathrm{C}$ & $\begin{array}{l}\text { Within } 48 \mathrm{hr}: 4^{\circ} \mathrm{C} \\
\text { Longer than } 48 \mathrm{hr}:-70^{\circ} \mathrm{C}\end{array}$ & \\
\hline $\begin{array}{l}\text { Lower respiratory tract specimen: } \\
\text { bronchial washing* }\end{array}$ & Sterile container & $4^{\circ} \mathrm{C}$ & $\begin{array}{l}\text { Within } 48 \mathrm{hr}: 4^{\circ} \mathrm{C} \\
\text { Longer than } 48 \mathrm{hr}:-70^{\circ} \mathrm{C}\end{array}$ & $\begin{array}{l}\text { Pathogens might be diluted; } \\
\text { however, the specimen can be } \\
\text { subjected to diagnostic testing }\end{array}$ \\
\hline $\begin{array}{l}\text { Lower respiratory tract specimens: } \\
\text { tracheal aspirate and transtracheal } \\
\text { aspirate }\end{array}$ & Sterile container & $4^{\circ} \mathrm{C}$ & $\begin{array}{l}\text { Within } 48 \mathrm{hr}: 4^{\circ} \mathrm{C} \\
\text { Longer than } 48 \mathrm{hr}:-70^{\circ} \mathrm{C}\end{array}$ & \\
\hline $\begin{array}{l}\text { Lower respiratory tract specimen: } \\
\text { lung biopsy }\end{array}$ & Sterile container with saline & $4^{\circ} \mathrm{C}$ & $\begin{array}{l}\text { Within } 48 \mathrm{hr}: 4^{\circ} \mathrm{C} \\
\text { Longer than } 48 \mathrm{hr}:-70^{\circ} \mathrm{C}\end{array}$ & \\
\hline Serum $^{\dagger}$ & $\begin{array}{l}\text { Serum separation test tube (SST): } \\
\text { adults and children, 3-5 mL; } \\
\text { infants, } 1 \mathrm{~mL}\end{array}$ & $4^{\circ} \mathrm{C}$ & $\begin{array}{l}\text { Within } 5 \text { days: } 4^{\circ} \mathrm{C} \\
\text { Longer than } 5 \text { days: }-70^{\circ} \mathrm{C}\end{array}$ & $\begin{array}{l}\text { For serological tests, a pair of } \\
\text { specimens is collected } \\
\text { Acute phase: within } 7 \text { days of } \\
\text { symptom onset } \\
\text { Convalescent period: } 14 \text { days } \\
\text { after collection during acute } \\
\text { phase } \\
\text { Dispensing of serum into another } \\
\text { container should be conducted } \\
\text { in a Class II or higher BSC }\end{array}$ \\
\hline
\end{tabular}

*Specimens recommended by the kit and approved by the Korea Ministry of Food and Drug Safety (MFDS) on March 13, 2020; ${ }^{\dagger}$ Specimens requiring advance consultation between the referrer and the laboratory.

Abbreviations: VTM, viral transport medium; NP, nasopharyngeal; OP, oropharyngeal; BSC, biosafety cabinet.

suspected cases or PUIs. As the clinical significance of co-infection caused by the causative agent of COVID-19 and other infectious diseases remains unclear, the collection of a sufficient quantity of clinical specimens with proper methods is recommended.

As the current knowledge on COVID-19 is limited, it is difficult to rule out infection based on a single negative test result, especially when the test is performed using an upper respiratory tract specimen. Even if the upper respiratory tract specimen tests negative, the collection and testing of lower respiratory tract specimens are strongly recommended, especially in cases of severe or progressive disease.

The collection of specimens for diagnosis is recommended within seven days of symptom onset. See Table 2 for information on specimen containers, transport conditions, and storage periods.

Upper respiratory tract specimen collection

Nasopharyngeal swab, oropharyngeal swab, nasopharyngeal aspirates, etc.
Lower respiratory tract specimen collection

Sputum*, bronchial washing, tracheal aspirates, transtracheal aspirates, bronchoalveolar lavage, transbronchial lung biopsy, etc.

*In cases with no purulent sputum, ensure that the individual breathes deeply and coughs straight into the container when providing the sputum specimen. Sputum induction is not recommended.

\section{Specimen selection $[4,14,15,17,18]$}

Asymptomatic patients and patients with mild symptoms

The collection of both nasopharyngeal swabs and oropharyngeal swabs is recommended; these should be placed together in the same viral transport medium (VTM) to increase the sensitivity $[14,19]$. However, the currently available VTM-swab systems are often designed for one swab. Therefore, specimen packaging and shipping should be conducted carefully, as there is a risk of leakage during transportation. When collecting only one specimen, a nasopharyngeal swab is recommended first. It may be necessary to collect lower respiratory tract specimens, such as sputum; however, sputum induction is not indicated. 
Table 3. Infection prevention and control for aerosol-producing procedures [28-30]

\section{Aerosol-producing procedures}

- Sputum collection, tracheal aspiration, bronchoscopy, continuous positive airway pressure therapy, removal of tracheal intubation, etc.

\section{Principles of infection prevention and control}

- Patient care should be performed with minimal medical staff.

- The following PPE should be used by personnel: N95 or KF94 mask or equivalent respirators, protective gown, disposable gloves, and eye protection (goggles or face shield).

- Personnel should adhere to the facility's hand hygiene policy before and after patient contact, as well as after removing PPE.

\section{Procedure site}

- A single, negative pressure room with > 12 air changes/hr is recommended for patient care. When this cannot be made available, a single room with natural ventilation and an average ventilation rate of $160 \mathrm{~L} / \mathrm{sec} /$ patient can be used.

- After using the single room, it should be disinfected according to the defined procedure and left vacant for a period of approximately 30 min (considering an air circulation rate of 12 air changes/hr).

- Entry to/exit from the room should be minimized during the procedure.

Abbreviation: PPE, personal protective equipment.

Patients with severe symptoms, patients with a productive cough, and intubated patients

Lower respiratory tract specimens, such as sputum, bronchoalveolar lavage, and tracheal aspirates, should be collected. If possible, the collection of nasopharyngeal and oropharyngeal swabs can be considered.

Patients referred for additional testing by a physician (e.g., patients who tested negative using nasopharyngeal or oropharyngeal swabs, but show an indication of pneumonia)

Lower respiratory tract specimens, such as sputum, bronchoalveolar lavage, and tracheal aspirates, should be collected.

\section{Other specimens}

If necessary, additional specimens, such as blood, urine, and feces, may be collected on consultation with the physician taking care of the patient and a laboratory physician. However, the diagnostic value and clinical utility of these specimens remain unclear. The collection of blood specimens may be considered for public health purposes, such as serological surveys. This may be amended based on new clinical evidence.

\section{Safety procedures during specimen collection}

The guidelines for the prevention of infection and control for aerosol-producing procedures should be followed when collecting specimens using aerosol-producing procedures, such as sputum collection, tracheal aspiration, and bronchoscopy (Table 3).

Collection of upper respiratory tract specimens, especially nasopharyngeal swab specimens, requires knowledge of the anatomical structure of the respiratory system and the collection process is also invasive. Hence, it is recommended that the collection be performed by medical personnel.

When collecting blood and other non-respiratory specimens from suspected or confirmed COVID-19 patients, laboratory personnel should wear personal protective equipment (PPE; N95 or KF94 mask, disposable gloves, gown [clean, covering the entire body, long-sleeves, back-closure], and eye protection [goggles or face shield]).

\section{SPECIMEN PACKING AND TRANSPORT}

\section{Specimen packing and transport within medical institutions} [18-20]

- The primary container should be sealed with a screw cap. The container should be made of plastic that has a low risk of breakage (e.g., a $50 \mathrm{~mL}$ conical tube or a VTM containing a cotton swab).

- Patient information should be recorded on the specimen container using two or more identifiers (e.g., name, patient number), along with the necessary information for testing requests. If the specimen information is erased on the barcode following disinfection with ethanol or is damaged, it should be recorded again for easy and accurate identification.

- The outer surface of the primary container should be disinfected using appropriate disinfectants such as 70\% ethanol. The container should be packed in a zipper bag and placed in a secondary container before transportation. The secondary container should be sealed and shock-resistant and should be labeled to indicate that it contains infectious sub- 
stances.

- When transporting specimens to a laboratory within the same institution, the specimens should be transported in person; the pneumatic tube system should not be used. A separate route should be used for transportation; it is recommended that an elevator be exclusively designated for such transportation. The personnel transporting the specimen should be trained in spill decontamination procedures in case of specimen leakage.

- If there are no visible leaks in the secondary container on receipt of a specimen, it can be reused after being disinfected using appropriate disinfectants such as $70 \%$ ethanol.

\section{External transport [19-21]}

- The triple packaging system (the UN3373 P650 packaging instructions) should be used.

- The primary container should be sealed with a screw cap and should be made of plastic that has a low risk of breakage.

- The outer surface of the primary container should be sterilized using appropriate disinfectants such as 70\% ethanol. The primary container should be covered with enough absorbent material and placed in a secondary container with the cap of the primary container facing upwards. The secondary container should be sealed with a sturdy cap such as a screw cap with an O-ring for waterproof and leakproof protection. The amount of absorbent should be enough to absorb the entire contents of the primary container in case of leakage.

- Cushioning materials, such as bubble wrap, should be placed in the outer packaging to reduce external impact during transportation. The secondary container should be fixed to prevent shaking. The specimen information sheet and the test request form should be placed between the secondary container and outer packaging. If necessary, information regarding the contents and amount of infectious material should be attached to the surface of the secondary container.

- The surface of the tertiary container should display the sender and recipient contact details, in case of emergency, as well as a UN3373 label indicating a Category B infectious substance.

- For further detailed guidelines not provided here, please refer to the latest edition of the "Guidance for laboratory biosafety related to coronavirus disease 2019" available on the KCDC website [21].

\section{SPECIMEN HANDLING AND TESTING PROCEDURES [14, 15, 20-25]}

- Personnel collecting the specimens should wear appropriate PPE (N95, KF94, or equivalent respirators, protective clothing, disposable gloves, etc.) and handle the specimens in a Class II or higher biosafety cabinet (BSC) at a biosafety level 2 (BL2) laboratory. Aerosol-producing procedures should always be performed within the BSC. If the container has to be opened outside of the BSC, PPE, such as an N95, KF94, or a higher-grade respirator (powered air-purifying respirator recommended), should be worn by the personnel and the bench should be disinfected after the procedure.

- Specimens that are subjected to nucleic acid extraction or inactivation in the BSC can be handled outside of the BSC in accordance with standard precautions for conventional specimens.

- The test method should comply with the standard operating procedures used by each laboratory and the manufacturer's instructions. Currently, clinical laboratories are using various nucleic acid extraction methods and reagents for real-time RT-PCR with EUA for COVID-19 diagnosis, and there are variations in the procedures used for the diagnosis. These guidelines do not present opinions regarding the selection of specific test methods or detailed test items. KSLM provides expert opinions on the detailed test items in the $Q \& A$ section of its website (http://www.kslm.org/rang_board/list.html?code= covid19_qna).

- When using commercially available products, the manufacturer's instructions and all other appropriate measures should be followed and care should be taken to prevent cross-contamination during nucleic acid extraction and addition to reagents. All procedures should comply with laboratory biosafety guidelines. Personnel should wear PPE (N95 or KF94 mask, disposable gloves, gown [covering the entire body, long-sleeves, and back-closure], and eye protection) in an isolated BL2 or higher laboratory. The use of automated equipment for nucleic acid extraction, which enables extraction outside of the BSC, is recommended. If an automated nucleic acid extraction system is not used, the procedure should be performed in a Class II or higher BSC.

- At the end of the procedure or when the specimen is contaminated, the bench should be disinfected using appropriate disinfectants (70\% ethanol, 2\% glutaraldehyde, sodium hypochlorite [chlorine concentration $0.05 \%, 500$ ppm], or other common virus disinfectants). Other disinfectants ap- 
proved by the Korea Ministry of Environment may also be used. The manufacturer's recommendations for dilutions and contact times should be followed.

- Waste handling: all infectious waste, including residual specimens, should be disposed off in accordance with the Korea Ministry of Environment's guidelines [25]. Residual specimens that tested negative using the COVID-19 testing can be disposed off according to the Ministry of Environment's guidelines for disposal of waste generated during routine testing.

\section{TEST INTERPRETATION}

\section{General guidelines for interpreting COVID-19 real-time RT- $\mathrm{PCR}^{*}$}

*Intended for commercial kits with EUA as of March 25, 2020

Criteria for determining positive and negative results in the screening and confirmatory tests

Positive control (+), negative control (-)

- Threshold cycle (Ct) value of the target gene $\leq$ cut-off Ct value: positive for the gene*.

- No target gene detected or Ct value >cut-off Ct value: negative for the gene*.

*Independent of internal control amplification

All results of negative control (+) or positive control (-) Invalid regardless of target gene and internal control amplification; retest is necessary. See details below.

Note: Values close to the cut-off values in specimens with low viral loads may indicate false-negative or false-positive results. Thus, a laboratory physician should interpret the results and if necessary, retest using residual or new specimens.

\section{Criteria for final test interpretation}

All kits currently available in Korea can detect two or more genes. According to the interpretation criteria of some manufacturers, detection of only one of multiple genes is interpreted as COVID-19 positive. However, based on results from actual clinical specimens, KSLM recommends a determination of a positive result only when all genes are detected. When only one gene is detected, retesting or consulting the reference laboratory is recommended.

1) Screening test $(+)$ and confirmatory test $(+)$ : positive for COVID-19 (SARS-CoV-2 detected).
Among the reagents with EUA, some kits with three target genes use one target gene for the screening test and the other two target genes for the confirmatory test. For these kits, the confirmatory test result is deemed positive only if both confirmatory genes are detected. If one gene is not detected, the result cannot be interpreted as positive.

2) Screening test (+) and confirmatory test (-): negative for COVID-19 (SARS-CoV-2 not detected).

For kits using betacoronavirus primers for the screening test, there is a possibility of betacoronavirus rather than SARS-CoV-2.

3) Screening test (-) and confirmatory test (-): negative for COVID-19 (SARS-CoV-2 not detected).

If the internal control is also negative, the result is invalid, and a retest is necessary.

4) Screening test (-) and confirmatory test (+): retest or refer to a reference laboratory for additional testing.

\section{Considerations}

At present, there is very limited knowledge regarding the timing of virus detection in COVID-19 cases. Hence, it is difficult to rule out COVID-19 based solely on one negative result, especially when using an upper respiratory tract specimen from a suspected case. Other upper respiratory tract specimens should be collected and tested when a highly suspected COVID-19 patient tests negative using a single upper respiratory tract specimen. The lower respiratory tract specimens may be collected together and tested. Some considerations for possible false negative results are listed below:

Possible causes of false negative results $[4,26]$

- Inadequate specimen quality.

- Specimens collected too early or too late.

- Specimens improperly handled or transported.

- Occurrence of viral genetic mutation.

- Presence of PCR inhibitors.

- Antiviral administration prior to testing.

\section{Solutions}

- If the upper respiratory tract specimens test negative, lower respiratory tract specimens should be collected and tested.

- Patient specimens, a positive control, and a negative control should be examined together, and internal controls should 
be examined and verified together in all reactions.

- If a patient with an epidemiological correlation and COVID-19 symptoms repeatedly tests negative, the tested specimen should be submitted to the KCDC for further testing.

\section{REPORT [26]}

(1) Basic information regarding the collected specimen Patient name, age (date of birth), sex, patient number (hospital number), specimen number, ward, test order date, specimen type, and specimen collection time.

\section{(2) Results}

- Negative

- Indeterminate, Inconclusive, Equivocal ${ }^{*}$ : retesting is recommended using new specimens.

*These guidelines do not clearly differentiate these terms.

The laboratory physician can decide the term to use.

- Positive: should be reported immediately.

(3) Note: Any unusual findings such as those regarding specimen quality.

(4) Reporting time

\section{LABORATORY GUIDELINES FOR BIOSAFETY AND INFECTION CONTROL}

\section{General information [14, 15, 20-24, 27-29]}

PPE

- The personnel collecting the specimens should follow the standard precautions for handling all potentially infectious specimens. The personnel should wear disposable gloves, a gown (covering the entire body, long-sleeved, and containing a back-closure), mask (surgical mask, dental mask, etc.), and goggles or face shield (should be worn on top of the glasses when there is a risk of splashing from opening the specimen container).

- When there is a high risk of aerosol production, respiratory protection higher than N95 or KF94 should be used. When wearing a respirator, a fit test should always be employed to ensure proper usage.

- The use of respirators and face masks is not necessary when working inside a BSC; however, they can still be used considering the additional risks.

- Once testing is completed, all protective equipment should be removed, and hands should be washed before leaving the testing area.

- Protective equipment should be removed carefully so as not to contaminate the hands and body.

Working area and equipment

- Aerosol-generating procedures (e.g., vortex agitation) should be performed inside a certified Class II or higher BSC. Centrifuges should be equipped with a double cover, safety buckets, and sealed rotors, which are physically sealed and require the insertion or removal of centrifuge tubes into buckets and rotors for centrifugation. Procedures conducted outside of the BSC should ensure minimal exposure.

- After handling the specimens, the work area and equipment should be disinfected with $70 \%$ ethanol or other suitable disinfectants.

- Consumables that are contacted with infectious specimens should be disposable.

- All infectious waste should be disposed off in accordance with the Ministry of Environment's "Specific measures for the management of coronavirus disease 2019 quarantine medical waste" guidelines [25].

- Residual specimens that test negative in the COVID-19 testing can be disposed off following the Ministry of Environment's guidelines for disposal of waste generated during routine testing [24].

\section{COVID-19 biosafety measures $[14,15,20-24,27]$}

The following procedures should be performed only in BL3 or higher facilities

- Virus isolation in cell culture.

- Manipulation of live virus isolates.

The following procedures should be performed only in BL2 or higher facilities and in a certified Class II or higher BSC

- Aliquoting or diluting specimens.

- Inoculating bacterial or mycological culture media.

- Performing diagnostic testing that does not involve the propagation of viral agents.

- Nucleic acid extraction procedures for infectious specimens.

- Preparation and chemical- or heat-fixing of smears for microscopic testing.

- Rapid antigen test on urine or respiratory specimens.

The following procedures should be performed in BL2 or higher facilities 
- Pathological examination of formalin-fixed or otherwise inactivated tissues.

- Molecular testing of extracted nucleic acid preparations.

- Electron microscopy examination of glutaraldehyde-fixed specimens.

- Routine examination of bacterial and fungal cultures.

-Microscopy of fixed specimens.

- Final packaging of infectious specimens already sealed in a secondary container.

- Procedures using inactivated specimens (e.g., specimens in nucleic acid extraction buffer).

Routine tests (hematological tests, biochemical tests, etc.)

- When performing routine tests (hematological tests, biochemical tests, serological tests, etc.) on blood, serum, or urine specimens, after performing a risk assessment considering the risk of infectious aerosol, the specimens can be handled in the same way as that used for general clinical specimens in appropriate cases.

- In general, decapping is considered a low-risk procedure. However, it depends on the design of the lid and container. Whether to proceed with the testing will be determined following a risk assessment, which takes into account the need for centrifugation, mixing, and aliquoting. In addition, the use of a BSC should be considered at any time when there is a high risk.

- Point-of-care testing, such as blood-gas analysis, should also be performed once safety is confirmed through a risk assessment.

- Automated analyzers should be sterilized according to the laboratory manual after specimen treatment or before regular maintenance checks.

- A certified BSC should be used while counting cells or making smears using body fluids other than blood (e.g., cerebrospinal fluid).

- Respiratory specimens and any other specimens should be processed in a certified Class II or higher BSC.

\section{ACKNOWLEDGEMENTS}

None.

\section{AUTHOR CONTRIBUTIONS}

$\mathrm{KHH}$ and SWL reviewed the current information regarding the general recommendations and wrote this manuscript. TSK, JSK, and GJK reviewed and wrote the biosafety guideline section. $J H L, H S S$, and JSP collected the current information regarding specimen collection and transportation. HJH, SYK, KHR, MWS, HSK, STL, and NR collected the current information regarding protocols and interpretation of results and provided the current recommendation. $\mathrm{HL}, \mathrm{KCK}$, and $\mathrm{CKY}$ organized the task force and contributed to the concept and the design of the guidelines.

\section{AUTHORS' DISCLOSURES OF POTENTIAL CONFLICTS OF INTEREST}

No potential conflicts of interest relevant to this article were reported.

\section{RESEARCH FUNDING}

None.

\section{ORCID}

Ki Ho Hong

Sang Won Lee

Taek Soo Kim

Hee Jae Huh

Jaehyeon Lee

So Yeon Kim

Jae-Sun Park

Gab Jung Kim

Heungsup Sung

Kyoung Ho Roh

Jae-Seok Kim

Hyun Soo Kim

Seung-Tae Lee

Moon-Woo Seong

Namhee Ryoo

Hyukmin Lee

Kye Chul Kwon

Cheon Kwon Yoo https://orcid.org/0000-0002-5700-9036

https://orcid.org/0000-0003-0027-0134

https://orcid.org/0000-0002-2093-1721

https://orcid.org/0000-0001-8999-7561

https://orcid.org/0000-0003-3211-8903

https://orcid.org/0000-0003-1774-0382

https://orcid.org/0000-0002-2746-9162

https://orcid.org/0000-0002-6284-428X

https://orcid.org/0000-0002-6062-4451

https://orcid.org/0000-0002-6291-9229

https://orcid.org/0000-0001-6025-0341

https://orcid.org/0000-0002-7026-6715

https://orcid.org/0000-0003-1047-1415

https://orcid.org/0000-0003-2954-3677

https://orcid.org/0000-0001-8383-709X

https://orcid.org/0000-0002-8523-4126

https://orcid.org/0000-0002-4886-0590

https://orcid.org/0000-0002-8444-3620

\section{REFERENCES}

1. Chen N, Zhou M, Dong X, Qu J, Gong F, Han Y, et al. Epidemiological and clinical characteristics of 99 cases of 2019 novel coronavirus pneumonia in Wuhan, China: a descriptive study. Lancet 2020;395:507-13.

2. Coronaviridae Study Group of the International Committee on Taxonomy of Viruses. The species severe acute respiratory syndrome-related coronavirus: classifying 2019-nCoV and naming it SARS-CoV-2. Nat Microbiol. 2020 Mar 2. doi: 10.1038/s41564-020-0695-z. (Epub ahead of 
print).

3. Korea Centers of Disease Control and Prevention. Guidelines in response to coronavirus disease 2019. 7-3rd ed. (for local government). https://www.cdc.go.kr/board/board.es?mid=a20507020000\&bid=0019 \&act=view\&list_no=366558\&tag=\&nPage $=1$ (Updated on March 15, 2020).

4. World Health Organization. Laboratory testing for coronavirus disease 2019 (COVID-19) in suspected human cases: interim guidance. https:// www.who.int/publications-detail/laboratory-testing-for-2019-novel-coronavirus-in-suspected-human-cases-20200117 (Updated on March 19, 2020).

5. Chu DKW, Pan Y, Cheng SMS, Hui KPY, Krishnan P, Liu Y, et al. Molecular diagnosis of a novel coronavirus (2019-nCoV) causing an outbreak of pneumonia. Clin Chem. 2020 Jan 31. pii: hvaa029. doi: 10.1093/ clinchem/hvaa029. (Epub ahead of print).

6. Corman VM, Landt O, Kaiser M, Molenkamp R, Meijer A, Chu DKW, et al. Detection of 2019 novel coronavirus (2019-nCoV) by real-time RTPCR. Euro Surveill 2020;25:2000045.

7. Department of Medical Sciences, Ministry of Public Health, Thailand. Diagnostic detection of novel coronavirus 2019 by real time RT-PCR. https://www.who.int/docs/default-source/coronaviruse/conventional-rtpcr-followed-by-sequencing-for-detection-of-ncov-rirl-nat-inst-health-t. pdf (Updated on January 23, 2020).

8. Institut Pasteur. Protocol: real-time RT-PCR assays for the detection of SARS-CoV-2. https://www.who.int/docs/default-source/coronaviruse/real-time-rt-pcr-assays-for-the-detection-of-sars-cov-2-institut-pasteurparis.pdf (Updated on March 2, 2020).

9. Centers for Disease Control and Prevention. Real-time RT-PCR panel for detection 2019-Novel Coronavirus. https://www.cdc.gov/coronavirus/2019ncov/downloads/rt-pcr-panel-for-detection-instructions.pdf (Updated on February 4, 2020).

10. Wang D, Hu B, Hu C, Zhu F, Liu X, Zhang J, et al. Clinical characteristics of 138 hospitalized patients with 2019 novel coronavirus-infected pneumonia in Wuhan, China. JAMA. 2020 Feb 7. doi: 10.1001/ jama.2020.1585. (Epub ahead of print).

11. Zhu N, Zhang D, Wang W, Li X, Yang B, Song J, et al. A novel coronavirus from patients with pneumonia in China, 2019. N Engl J Med 2020; 382:727-33.

12. National Institute for Viral Disease Control and Prevention. Specific primers and probes for detection 2019 novel coronavirus. http://ivdc. chinacdc.cn/kyjz/202001/t20200121_211337.html (Updated on January 21, 2020).

13. Vijgen L, Moës E, Keyaerts E, Li S, Van Ranst M. A pancoronavirus RTPCR assay for detection of all known coronaviruses. Methods Mol Biol 2008;454:3-12.

14. World Health Organization. Coronavirus disease (COVID-19) technical guidance: laboratory testing for 2019-nCoV in humans. https://www. who.int/emergencies/diseases/novel-coronavirus-2019/technical-guidance/laboratory-guidance (Updated on March 2, 2020).

15. Public Health England. Guidance COVID-19: safe handling and processing for laboratories. https://www.gov.uk/government/publications/ wuhan-novel-coronavirus-guidance-for-clinical-diagnostic-laboratories/ wuhan-novel-coronavirus-handling-and-processing-of-laboratory-specimens (Updated on March 20, 2020).

16. Public Health Ontario. Coronavirus disease 2019 (COVID-19) testing. https://www.publichealthontario.ca/en/laboratory-services/test-informa- tion-index/wuhan-novel-coronavirus (Updated on March 17, 2020).

17. Zou L, Ruan F, Huang M, Liang L, Huang H, Hong Z, et al. SARS-CoV-2 viral load in upper respiratory specimens of infected patients. N Engl J Med 2020;382:1177-9.

18. Korea Centers for Disease Control \& Prevention. Guidelines for collecting clinical specimens for 2019 novel Coronavirus. https://www.cdc. go.kr/board/board.es?mid=a20507020000\&bid=0019\&act=view\&list_ no=365851 (Updated on January 23, 2020)

19. Centers for Disease Control and Prevention. Interim guidelines for collecting, handling, and testing clinical specimens from persons for coronavirus disease 2019 (COVID-19). https://www.cdc.gov/coronavirus/2019nCoV/lab/guidelines-clinical-specimens.html (Updated on March 21, 2020).

20. Ki CS, Lee H, Sung H, Kim S, Seong MW, Yong D, et al. Korean Society for Laboratory Medicine practice guidelines for the molecular diagnosis of Middle East respiratory syndrome during an outbreak in Korea in 2015. Ann Lab Med 2016;36:203-8.

21. Korea Centers of Disease Control and Prevention. Guidance for laboratory biosafety related to coronavirus disease 2019. 2nd ed. https://www. cdc.go. $\mathrm{kr} /$ board/board.es?mid=a40301000000\&bid=0014\&act=view\&li st_no=365920 (Updated on March 4, 2020).

22. Chosewood CL and Wilson DE, eds. Biosafety in microbiological and biomedical laboratories. United States Department of Health and Human Services, Public Health Service, Centers for Disease Control and Prevention, National Institutes of Health, 2009.

23. World Health Organization. Laboratory biosafety guidance related to coronavirus disease 2019 (COVID-19): interim guidance. https://apps. who.int/iris/handle/10665/331138 (Updated on February 12, 2020).

24. Centers for Disease Control and Prevention. Interim laboratory biosafety guidelines for handling and processing specimens associated with coronavirus disease 2019 (COVID-19). https://www.cdc.gov/coronavirus/2019nCoV/lab/lab-biosafety-guidelines.html (Updated on March 18, 2020).

25. Korea Ministry of Environment. Specific measures for the management of coronavirus disease 2019 quarantine medical waste. 3rd ed. https:// www.cdc.go.kr/board/board.es?mid=a20507020000\&bid=0019\&act=vi ew\&list_no=366425 (Updated on March 3, 2020).

26. CLSI. Molecular diagnostic methods for infectious diseases. 3rd ed. CLSI MM03. Wayne, PA: Clinical and Laboratory Standards Institute. 2015.

27. World Health Organization. Laboratory biosafety manual. 3rd ed. Geneva: World Health Organization, 2004. https://www.who.int/csr/resources/ publications/biosafety/Biosafety7.pdf

28. Pan American Health Organization. Requirements and technical specifications of personal protective equipment (PPE) for the novel coronavirus (2019-ncov) in healthcare settings. https://iris. paho.org/handle/10665.2/51906 (Updated on February 6, 2020).

29. World Health Organization. Rational use of personal protective equipment (PPE) for coronavirus disease (COVID-19): interim guidance. https://apps.who.int/iris/handle/10665/331498 (Updated on March 19, 2020).

30. World Health Organization. Infection prevention and control during health care when COVID-19 is suspected: interim guidance. https:// www.who.int/publications-detail/infection-prevention-and-control-during-health-care-when-novel-coronavirus-(ncov)-infection-is-suspected-20200125 (Updated on March 19, 2020). 